\title{
Conductivity Studies and Characterizations of PVA-Orthophosphoric Electrolytes
}

\author{
Lawal Sa'adu ${ }^{1}$, M. A. Hashim ${ }^{1}$, Masbudi bin Baharuddin ${ }^{1}$ \\ ${ }^{1}$ Faculty of Science and Technology, Universiti Sains Islam Malaysia (USIM), Malaysia \\ Correspondence: Lawal Sa’adu, Faculty of Science and Technology, Universiti Sains Islam Malaysia (USIM), \\ Bandar Baru Nilai, Negeri Sembilan 71800, Malaysia. E-mail: lawals2004@gmail.com
}

Received: June 19, 2014 Accepted: July 9, 2014 Online Published: July 24, 2014

doi:10.5539/jmsr.v3n3p48

URL: http://dx.doi.org/10.5539/jmsr.v3n3p48

\begin{abstract}
Solid polymer electrolyte (SPEs) has drawn great attention nowadays, particularly in the field of science and applied science, specifically, those used as separators in industries and researchers for the assemblage of some "classified batteries" and super capacitors. In this report, we present the grandeur of this SPE (pure type), particularly at room temperature, such that, it can be applied as an electrolyte as well as a separator in supercapacitor fabrication. The SPEs were produced from the composition of polyvinyl alcohol (PVA) and Phosphoric acid $\left(\mathrm{H}_{3} \mathrm{PO}_{4}\right)$, such that, the PVA samples were kept constant while the phosphoric acid was varied at 0 , $10,20,30,40,50,60$, and $70 \mathrm{wt} . \%$. After the experimentation, the pure polymers show excellent results in term conductivity, in that, it has recorded a conductivity as high as $2.56 \times 10^{-3} \mathrm{Scm}^{-1}$ at the compositions of $70 \mathrm{wt} . \%$. Aside that, we also observed that, the bulk moduli $\left(R_{\mathrm{b}}\right)$ value decreases with the increase in concentration, with pure solid polymer electrolyte (PSPE) recording $2.5 \Omega$ at the highest composition of $70 \mathrm{wt} . \%$.
\end{abstract}

Keywords: Pure solid polymer electrolyte (PSPE), polyvinyl alcohol (PVA), Phosphoric acid $\left(\mathrm{H}_{3} \mathrm{PO}_{4}\right)$, Electrochemical Impedance Spectroscopy (EIS).

\section{Introduction}

The year 2013 marked the complete three decades (1973) of the invention of polymer electrolyte by Fenton and co-workers (Gu et al., 2000; Kumar \& Sundari, 2010; Zhang et al., 2006; Yang, 2004; Ragavendran et al., 2004; Tripath et al., 2012; Ulaganathan et al., 2012; Kuo et al., 2013; Yang et al., 2013; Noor et al., 2010) and Armand (Ragavendran et al., 2004; Zhang et al., 2006). Ever since then, research on polymer electrolyte has become very elaborate.

Research has shown that, there are three classifications of polymer electrolyte systems, namely (i) Polyelectrolytes (PEs): - which have an independent ion-generating groups chemically bond to the macromolecular chain and presence of counter-ion in order to maintain the electroneutrality of the salt. In dry conditions, they have low conductivity of about $10^{-10}-10^{-15} \mathrm{Scm}^{-1}$ but in the presence of dielectric solvent such as water, there conductivities do improve (Ulaganathan et al., 2012). (ii) Solvent Swollen Polymer Electrolytes (SSPE): - In SSPE, solvents, both aqueous and non-aqueous swells the host polymer. Thus, the dopant ionic solutes such as $\mathrm{H}_{3} \mathrm{PO}_{4}$ is hosted in the swollen lattice thereby permitting the movement of ions in the solvent swollen region of the polymer host. Their conductivity depends on the compactness of the solvent in the region that is being puffed up (Ulaganathan et al., 2012). And lastly (iii) the Solvent Free Polymer Electrolytes (SFPE): These are polymer salt complex, which is formed by complexes between salts of alkali metals and polymer containing solvating hetroatoms, example; $\mathrm{O}, \mathrm{S}$ and N (Ulaganathan et al., 2012). The complexation between poly ethylene oxide (PEO) and alkali metal salts is a good example of SFPE. SFPE are sub-classed into three also. They are; (a) Solid Polymer Electrolytes (SPEs), (b) Gel Polymer Electrolytes (GPEs), and (c) Composite polymer electrolytes (CPEs) (Kuo et al., 2013; Tripath et al., 2012).

GPEs can be only considered as plasticizers incorporated polymer-salt complex (Ulaganathan et al., 2012). They are therefore consisted of a liquid electrolytes immobilized in a polymer matrix (Hashmi, (a), 2013) and exhibits high ionic conductivity $\left(10^{-3}\right.$ to $10^{-4} \mathrm{Scm}^{-1}$ at ambient temperature) and can be obtained by either loading of a liquid electrolyte in a microporous matrix or by increasing the viscosity of a liquid electrolyte through the addition of a soluble polymer until gel consistency is achieved or by mixing a liquid electrolyte with monomers of relatively low molecular weight, then curing the mixture by other means, such as UV polymerization, thermal 
polymerization and electron beam radiation polymerization. They are criticized for having weak mechanical strength and poor interracial properties, (Qiu et al., 2004; Hashmi, (b), 2013). In CPEs, they are normally prepared by addition of high surface inorganic filters like $\mathrm{SiO}_{2}, \mathrm{MgO}, \mathrm{TiO}_{2}$ and alike so as to improve the mechanical strength and stiffness of the complex systems (Ulaganathan et al., 2012).

SPE is a thin film that has ionic conductivity, especially, when an alkali, salt dissolves in polymer matrix. SPE have drawn great attention in the development of science and technology of lithium secondary batteries. SPEs have several advantages over liquid, gel and even composite electrolytes in that, it has process ability, flexibility, light weight, elasticity and transparency (Zhang et al., 2006), desirable shape moldability, being free from leakage, mechanical strength, better stability especially in high temperature, and high specific energy and power (Lim et al., 2012). Furthermore, use of use of solid polymer electrolyte can negate the need for a separator and be amendable to low cast manufacturing technologies (Qiu et al., 2004). Some of the applications of SPE are in Batteries, fuel cell, supercapacitors and other electrochemical devices. (Sawada et al., 2000) and other electrochemical devices (Sotta et al., 2010).

Although number of works have been carried out on the characterizations of SSPE like those of Prajapati et al., (2010) and Ahmad Khiar \& Arof, (2010), this piece tries to offer a tone by step approach on the conductivity studies of this transparent polymer in order to ascertain the suitability composition for the usage in the supercapacitor fabrication which is the main target of our future work. Thus, careful measures have been put in place to ensure that every detail characteristic of the active materials, especially of the PVA - its molecular weight and its percentage hydrolysis - were taken into considerations.

\section{Experimental}

\subsection{Preparation of the Composite PVA Electrolytes}

The pure solid polymer electrolyte (PSPE) which can also be served as separators in supercapacitors fabrications have their laboratory preparations discussed elsewhere by us, in Hashim et al., (2012), Hashim et al., (2014) and by Jiang et al., (2013). But for the purpose of elaboration; the active materials comprise of $\mathrm{H}_{3} \mathrm{PO}_{4}$ and PVA. The $\mathrm{H}_{3} \mathrm{PO}_{4}$ functions as an ionic liquid, while PVA acts as a polymeric matrix, allowing ionic transport while simultaneously functioning as a separator between the electrodes of the supercapacitor. $\mathrm{H}_{3} \mathrm{PO}_{4}(>85 \mathrm{wt}$. \% in water, molar mass of $98.00 \mathrm{~g} / \mathrm{mol}$, product, number of 1502-80) was obtained in aqueous form, from R \& M marketing, Essex, UK brand, while the PVA (molecular weight; 89,000-98,000, 99+ \% hydrolyzed) was obtained from Sigma Aldrich. Both $\mathrm{H}_{3} \mathrm{PO}_{4}$ and PVA were used as-received without further treatment or purification. An aqueous solution of PVA is prepared by combining PVA with distilled water in the ratio of 1:10 by volume. This solution is mechanically agitated by magnetic stirring at $60{ }^{\circ} \mathrm{C}$ for five hours to thoroughly dissolve the PVA in the distilled water. $\mathrm{H}_{3} \mathrm{PO}_{4}$ was then mixed with the PVA aqueous solution in the ratio of 100:0, 90:10, 80:20, 70:30, 60:40, 50:50, 40:60 and 30:70 wt. \% for the PSPE to be obtained (this has been summarized in Table 1).

In order to vary the percentage of the $\mathrm{H}_{3} \mathrm{PO}_{4}$ used, the following formula was used;

$$
\frac{n}{n+2} \times 100 \%=x \%
$$

Where $x$ is the percentage of acid require $(0,10,20,30,40,50,60$, and $70 \% \mathrm{wt})$, and $n$ is the value of $\mathrm{H}_{3} \mathrm{PO}_{4}$ in grams.

The mixing is done in a drop-wise manner with magnetic stirring at $60^{\circ} \mathrm{C}$ for about one hour or thereabouts until it completely turns to homogeneous solution (transparent in this case). The mixture is then allowed to cool down to an ambient temperature. The resulting homogeneous solution of $\mathrm{PVA} / \mathrm{H}_{3} \mathrm{PO}_{4}$ is cast over a plastic Petri dish. Prior to this, the Petri dish was scraped off the dust using a tissue soaked in acetone. The $\mathrm{PVA} / \mathrm{H}_{3} \mathrm{PO}_{4}$ solution solidifies onto the Petri dish and upon curing for about $3-4$ weeks at room temperature. This is due to its high molecular weight and consequently more hydrolyzed. The solid layer was easily peeled off from the Petri dish after it dries as a freestanding layer. The thickness of the solid layers formed in this procedure can be controlled depending on the composition that have been enumerated above and as shown in Figure 1. The resulting polymer film was then put in the plastic bags for safe keeping, and to avoid contamination from surrounding, for further property analysis.

\section{Result and Discussion}

\subsection{Conductivity and Chemical Composition Analysis}

Conductivity measurements were carried out on both the solid and hybrid polymer electrolyte films which are also composed of all the different percentage ratio of $\mathrm{PVA}-\mathrm{H}_{3} \mathrm{PO}_{4}$ an impedance method which also was highlighted by Ahmad Khiar and Arof (2010). The solid polymer films were sandwiched between a stainless steel, ion-blocking 
liked measuring device (otherwise known as a probe), each of surface area $2 \mathrm{~cm}^{2}$ in radius, in a spring-loaded glass holder.

The impedance measurements were carried out by using Electrochemical Impedance Spectroscopy (EIS) testing machine named HIOKI 3532-50 LCR Hi-Tester which was connected to the computer. The frequency range of the device was $50 \mathrm{~Hz}-1 \mathrm{MHz}$, and simultaneously calculating both real and imaginary impedance.

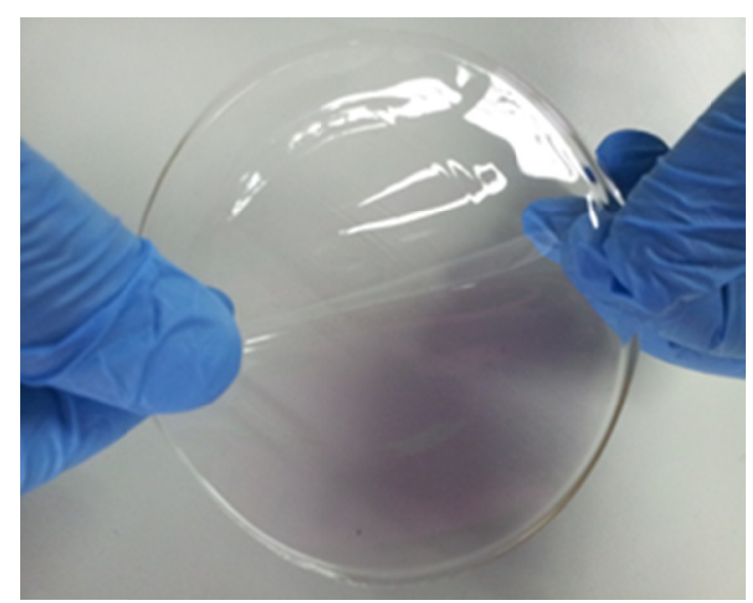

Figure 1. Showing a prepared and flexible PSPE

Table 1. Table Showing the Overall Formation of the PSPE Preparation

\begin{tabular}{lccc}
\hline Coding & $\begin{array}{c}\text { Measured Quantity PVA } \\
\text { in Distilled Water }(\mathrm{g})\end{array}$ & $\begin{array}{c}\text { Measured Quantity of } \\
\mathrm{H}_{3} \mathrm{PO}_{4}(\mathrm{~g})\end{array}$ & $\begin{array}{c}\text { Ratio of PVA to } \\
\mathrm{H}_{3} \mathrm{PO}_{4}\end{array}$ \\
\hline P0 & 2 & 0 & $100: 0$ \\
P10 & 2 & 0.22 & $90: 10$ \\
P20 & 2 & 0.50 & $80: 20$ \\
P30 & 2 & 0.86 & $70: 30$ \\
P40 & 2 & 1.33 & $60: 40$ \\
P50 & 2 & 2.00 & $50: 50$ \\
P60 & 2 & 3.00 & $40: 60$ \\
P70 & 2 & 4.67 & $30: 70$ \\
\hline
\end{tabular}

The sample exhibits Debye characteristics, and then the plots of the negative imaginary impedance versus the real impedance on the graph should be able to display a semicircle-like shape (Ahmad Khiar \& Arof 2010). From the Eq. 2, we calculated the electrical conductivity of the samples;

$$
\sigma=\frac{l}{R_{b} A}
$$

Where $\sigma$ is the conductivity itself, $l$ and $A$ are respectively the thickness and area of the samples. The thickness of the sample was measured twice at different positions of the polymer films and an average was taken using digital micrometer. 

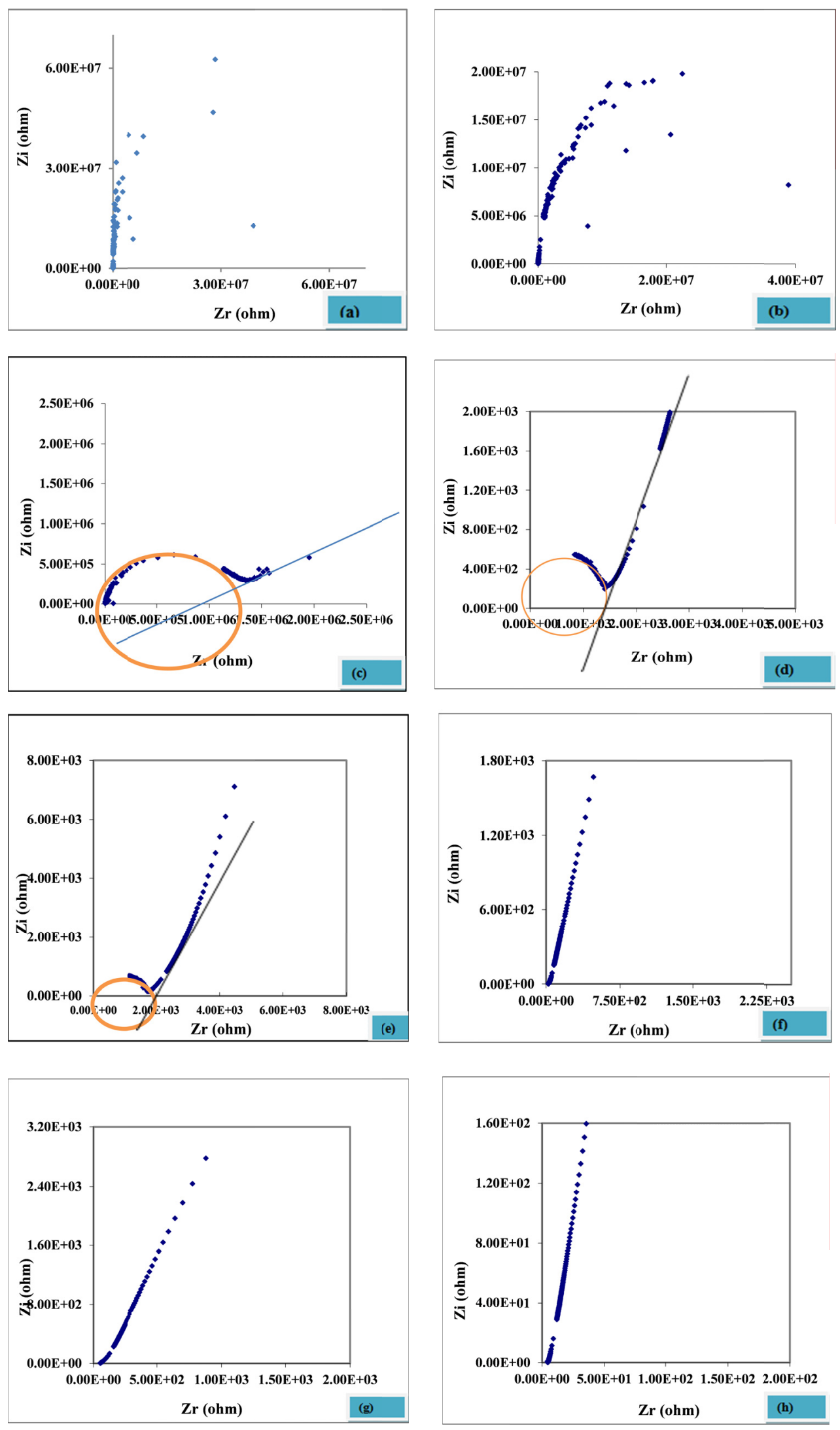

Figure 2. Impedance plots of PSPE containing 0 wt.\% (a); 10 wt.\% (b); 20 wt.\% (c); 30 wt.\% (d); 40 (e); 50 wt.\% (f); 60 wt.\% (g); 70 wt.\% (h) ratio of the $\mathrm{H}_{3} \mathrm{PO}_{4}$ at room temperatures 
Figure 2 (a-h) shows the impedance plots of a sample of the PSPE containing 0, 10, 20, 30, 40, 50, 60, and 70 wt. \% ratio of the $\mathrm{H}_{3} \mathrm{PO}_{4}$ at room temperatures respectively. For the sample with 0 and $10 \mathrm{wt} \%$ of the $\mathrm{H}_{3} \mathrm{PO}_{4}$, it can be observed that the point of the graph was dispersed, which clearly indicates the meager or absent of acid in this sample.

The semicircles found on the Figure of the samples containing 20, 30 and $40 \mathrm{wt} . \%$ could however be connected with the impact of the introduction of the percentage acid and consequently the immobile polymer chain begins to emerge.

As the acid concentration continues to increase, so the conductivity, thereby making the semicircle disappear, which is an indication that, ions that move around the polymer matrix made resistive component of the polymer electrolytes to exist. (Ahmad Khiar \& Arof, 2010; Ulaganathan et al., 2012).

The calculated $R_{\mathrm{b}}$ for all the eight samples above were obtained from the frequency intercepts on each and every plotted graph. We also observed that, the $R_{\mathrm{b}}$ value decreases with the increase in concentration. The calculated values of the $R_{\mathrm{b}}$ are $1.15 \times 10^{8}, 8.00 \times 10^{4}, 2.40 \times 10^{4}, 1.70 \times 10^{3}, 2.10 \times 10^{3}, 1.93 \times 10^{1}, 1.26 \times 10^{1}$ and $2.58 \Omega$ for $0,10,20,30,40,50,60$, and $70 \mathrm{wt} . \%$ ratio of the $\mathrm{H}_{3} \mathrm{PO}_{4}$ respectively. The highest conductivity of PSPE sample was observed at $2.56 \times 10^{-3} \mathrm{Scm}^{-1}$ when the $\mathrm{H}_{3} \mathrm{PO}_{4}$ was increased to $70 \mathrm{wt} . \%$ while the lowest conductivity of the sample was noticed at $2.25 \times 10^{-11} \mathrm{Scm}^{-1}$ where the $\mathrm{H}_{3} \mathrm{PO}_{4}$ percentage was nil. Full details about the average values of the conductivity of PSPE is summarized in Table 2. On a general note, it can be said that, the sample of PSPE performed wonderfully well in terms of both bulk resistance calculation and the conductivity as a whole.

As mentioned earlier, that conductivity is dependent on the concentration of the $\mathrm{H}_{3} \mathrm{PO}_{4}$. Table 2 provided us with the information that, there is a relationship between the acid concentration and the polymer matrix. In addition to that, it also be deduce from the table that, the thickness on each sample, also had some impact on the conductivity of the samples. Hence, because of the thinner nature of the films in PSPE, the conductivity seems to be very promising.

Table 2. Parameters that Determine the Conductivity in PSPE

\begin{tabular}{lcccc}
\hline Coding & PVA: $\mathrm{H}_{3} \mathrm{PO}_{4}$ & $1(\mathrm{~mm} \pm 0.005)$ & $\mathrm{R}_{\mathrm{b}}(\Omega)$ & $\sigma\left(\mathrm{Scm}^{-1}\right)$ \\
\hline P0 & $100: 0$ & 0.00910 & $1.15 \times 10^{8}$ & $2.25 \times 10^{-11}$ \\
P10 & $90: 10$ & 0.00630 & $8.00 \times 10^{4}$ & $7.20 \times 10^{-8}$ \\
P20 & $80: 20$ & 0.01100 & $2.40 \times 10^{4}$ & $1.46 \times 10^{-7}$ \\
P30 & $70: 30$ & 0.05400 & $1.70 \times 10^{3}$ & $1.01 \times 10^{-5}$ \\
P40 & $60: 40$ & 0.00585 & $2.10 \times 10^{3}$ & $8.87 \times 10^{-7}$ \\
P50 & $50: 50$ & 0.00745 & $1.93 \times 10^{1}$ & $1.23 \times 10^{-4}$ \\
P60 & $40: 60$ & 0.02615 & $1.26 \times 10^{1}$ & $6.61 \times 10^{-4}$ \\
P70 & $30: 70$ & 0.02070 & $2.58 \times 10^{0}$ & $2.56 \times 10^{-3}$ \\
\hline
\end{tabular}

\subsection{Crystal Structure Analysis}

The crystal structure analysis of the solid polymer electrolyte films was examined by a Philip X'Pert X-ray diffractometer (XRD) with $\mathrm{Cu} \mathrm{K} \mathrm{K}_{\alpha}$ radiation of wavelength $\lambda=1.54056 \AA$ for $2 \theta$ angles between $10^{\circ}$ and $80^{\circ}$. The XRD analysis was carried out on the PSPE films. After the analysis, the following results were obtained. The analysis of the structure of the PSPE for 0 wt.\% (a); 10 wt.\% (b); 20 wt.\% (c); 30 wt.\% (d); 40 wt.\% (e); 50 wt.\% (f); 60 wt.\% (g); 70 wt.\% (h) ratio of the $\mathrm{H}_{3} \mathrm{PO}_{4}$ was shown in Figure 3.

It can be observed from the semi-crystalline peak of the PVA $\left(\theta=20^{\circ}\right)$ which also affirmed the argument put across by (Hashmi, (c), 2013) about the semi-crystal behavior of the PVA. The addition of $\mathrm{H}_{3} \mathrm{PO}_{4}$ causes the decrease in the degree of the crystallinity and consequently the increase in the amorphicity of the material and its conductivity. 

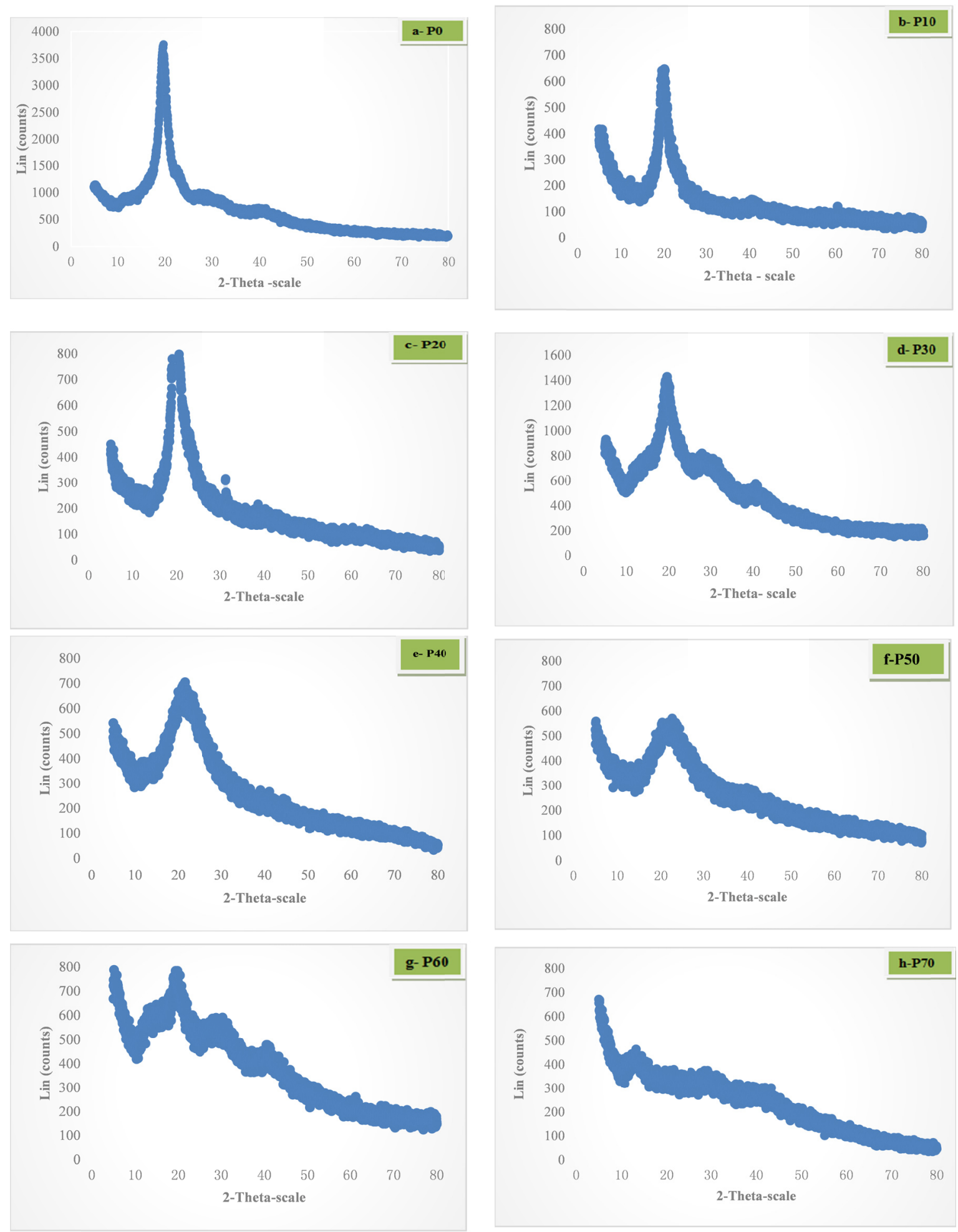

Figure 3. XRD Analysis of PSPE containing 0 wt.\% (a); 10 wt.\% (b); 20 wt.\% (c); 30 wt.\% (d); 40 wt.\% (e); 50 wt.\% (f); 60 wt. $\%$ (g); 70 wt.\% (h) ratio of the $\mathrm{H}_{3} \mathrm{PO}_{4}$ and (i) A combined graph containing all the percentages.

\subsection{Differential Scanning Calorimetry Analysis}

The DSC thermal analysis was carried out using the DCS machine (Mettler Toledo DSC A851 with Star software) under $\mathrm{N}_{2}$ atmosphere with $10{ }^{\circ} \mathrm{C} / \mathrm{min}$ heating rate from 40 to $300{ }^{\circ} \mathrm{C}$ in order to observe the crystalline and semi-crystalline behavior of the whole samples, therefore, various parameters related to thermal properties such as 
glass transition temperature $\left(\boldsymbol{T}_{g}\right)$, thermal transition $\left(\boldsymbol{T}_{m}\right)$ of crystalline phase of the polymer electrolytes and degree of crystallinity $\left(T_{c}\right)$ can be evaluated from the DSC data. Samples for DSC measurements were prepared from several tiny rectangular pieces cut from the polymer film to a mass ranging from 1.98 -24.24 mg for PSPE and $7.08-19.82 \mathrm{mg}$ for HSPE. The temperature range studied was -40 to $200^{\circ} \mathrm{C}$. The heating/cooling rate was $10{ }^{\circ} \mathrm{C} / \mathrm{min}$.

Table 3. Parameters for the Thermometric Analysis in PSPE

\begin{tabular}{lllllr}
\hline & & & \multicolumn{3}{c}{ Temperature $\left({ }^{\circ} \mathrm{C}\right)$} \\
\cline { 3 - 5 } Coding & PVA: ${ }_{3} \mathrm{PO}_{4}$ & Mass $(\mathrm{g})$ & $\mathrm{T}_{\mathrm{g}}$ & $\mathrm{T}_{\mathrm{m}}$ & $\mathrm{T}_{\mathrm{c}}$ \\
\hline P0 & $100: 0$ & 1.98 & 98.11 & 223.56 & 152.00 \\
P10 & $90: 10$ & 4.48 & 80.78 & 221.06 & 166.27 \\
P20 & $80: 20$ & 7.41 & 127.31 & 207.26 & 186.45 \\
P30 & $70: 30$ & 8.27 & 117.63 & 156.46 & - \\
P40 & $60: 40$ & 15.12 & 116.89 & 155.00 & - \\
P50 & $50: 50$ & 13.53 & 101.13 & 164.59 & 160.05 \\
P60 & $40: 60$ & 19.48 & 63.28 & 160.00 & 150.00 \\
P70 & $30: 70$ & 24.40 & 79.41 & 129.09 & 79.41 \\
\hline
\end{tabular}

Figure 4 shows the DSC analysis result of PSPE containing 0 wt. $\%$ (a); 10 wt. $\%$ (b); 20 wt.\% (c); 30 wt.\% (d); 40 wt.\% (e); 50 wt.\% (f); 60 wt.\% (g); 70 wt.\%. From the Figure and Table 3 it can be seen that, the first three samples show a very good $T_{m}$ with an endothermic peak of slightly above $200{ }^{\circ} \mathrm{C}$ (i.e. $233.56,221$ and 207.26 for P0, P10 and P20 respectively) which indicates the huge percentage weight of PVA is present here. Noting the theoretical value of the thermal transition of the pure PVA as $230{ }^{\circ} \mathrm{C}$, this result is closely related to that, and was in agreement with that of (Jelinska et al., 2010; Agrawal, 2004; Othman et al., 2011). However, probably due to the presence of chemical content, or intermolecular interaction (Mudigoudra et al., 2012) form among PVA and $\mathrm{H}_{3} \mathrm{PO}_{4}$, the thermal transition starts to decrease with the increase in temperature.

The higher the melting point temperature the more the stability of the molecules therein, as such, pure PVA has more stable molecules than PVA $/ \mathrm{H}_{3} \mathrm{PO}_{4}$ composite. So, it can be seen that the $T_{m}$ and $T_{c}$ decreases (or even diminishes) as the concentration of the acid increase. This is a known fact that, in homogenized blends, the melting shifts to the lower level (Othman et al., 2011; Guirguis \& Moselhey, 2012.). The other unusual humps cited in especially P0 and P60 could be as a result of the presence of the moisture inside the samples. Also the theoretical glass transition of the PVA alone is about $85{ }^{\circ} \mathrm{C}$ while the composite shows down and upwards shifts of this temperature. This could not be unconnected with the gradual increment in the concentration of the acid.

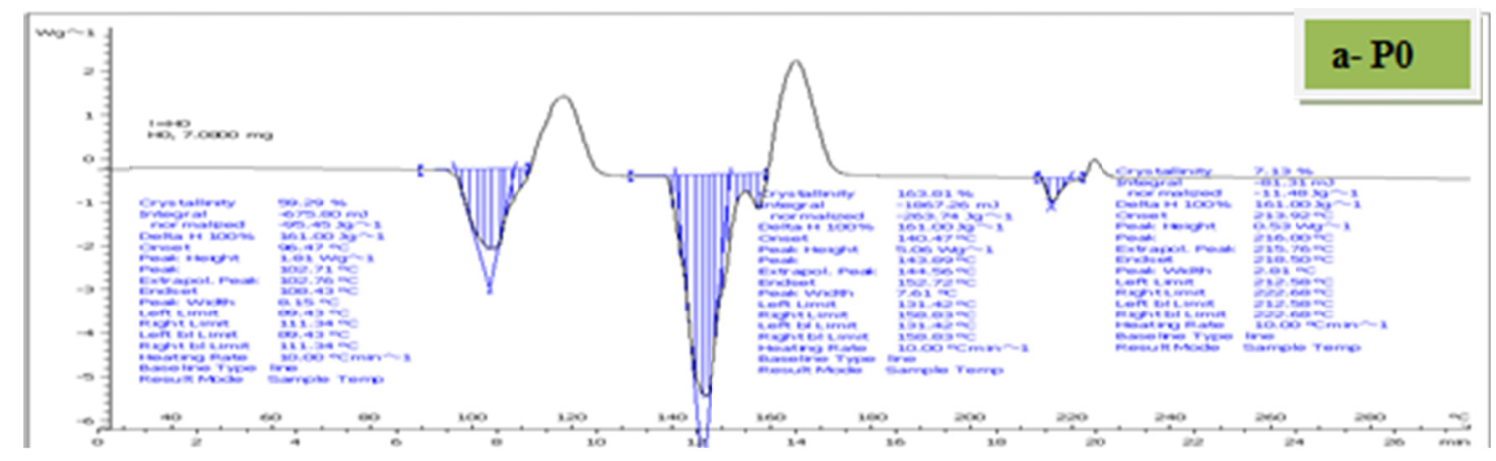



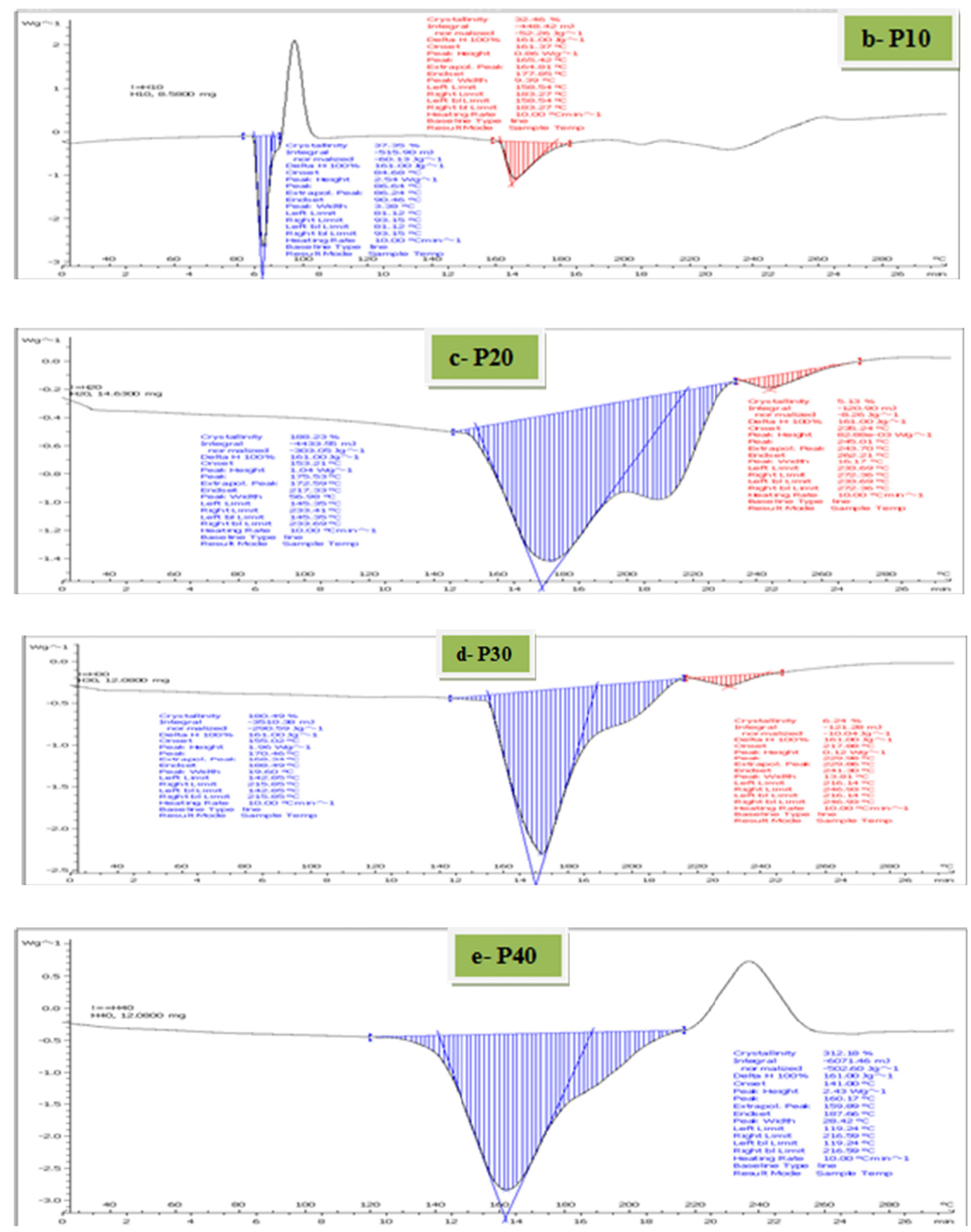

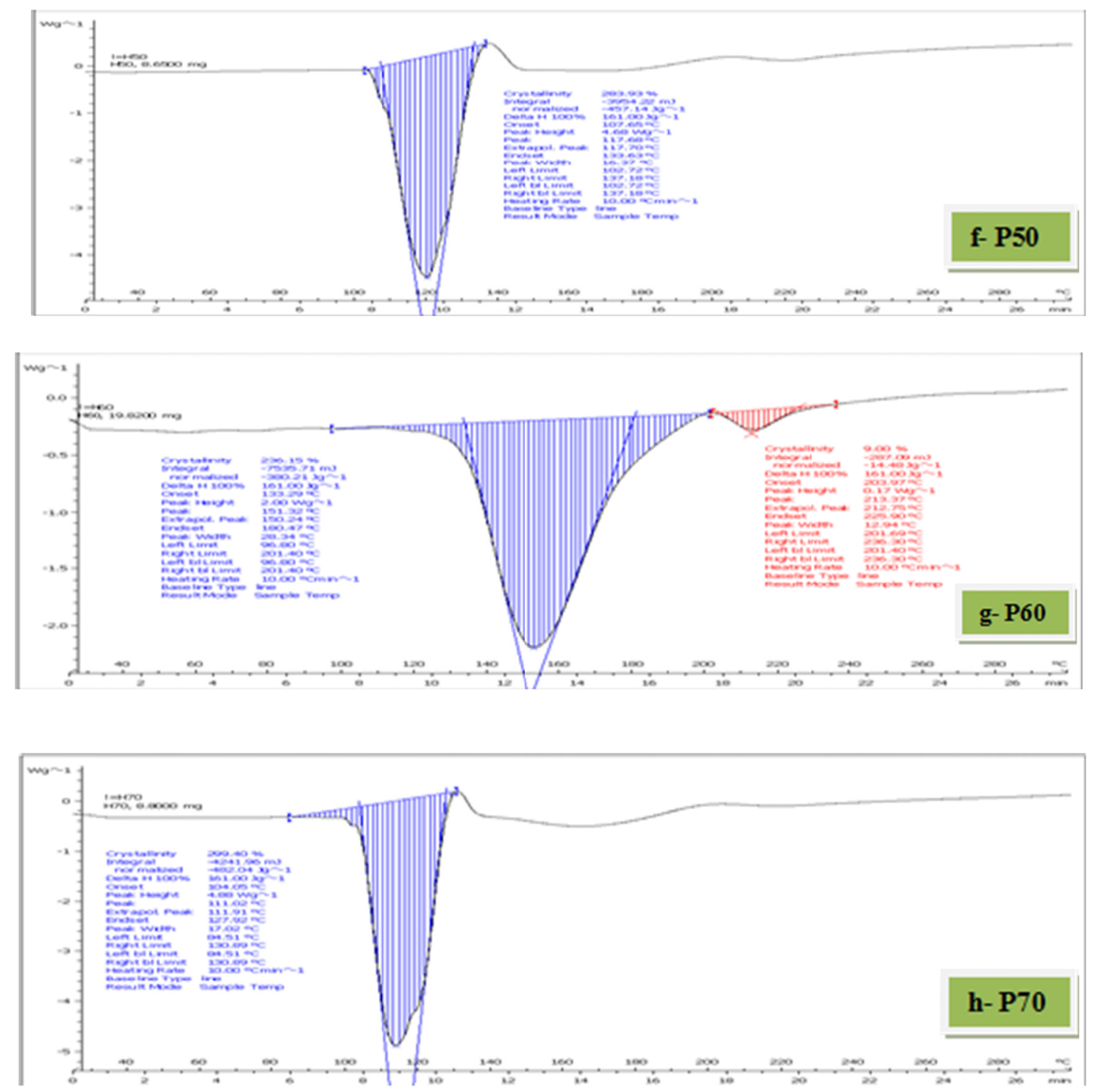

Figure 4. DSC Analysis of Solid (S) Solid Polymer electrolyte containing 0 wt.\% (a); 10 wt.\% (b); 20 wt.\% (c); 30 wt.\% (d); 40 wt.\% (e); 50 wt.\% (f); 60 wt.\% (g); 70 wt.\% (h)

\section{Conclusion}

In this study, we have introduced the noble of the pure solid polymer electrolyte at room temperature used as an electrolyte as well as a separator from the piece of PVA and $\mathrm{H}_{3} \mathrm{PO}_{4}$ such that, the PVA samples were kept constant while the phosphoric acid was varied at $0,10,20,30,40,50,60$, and $70 \mathrm{wt} . \%$. The PSPE results in higher conductivity of $2.56 \times 10^{-3} \mathrm{Scm}^{-1}$, at the compositions of $70 \mathrm{wt} . \%$, in addition to that, we also observed that, the bulk modulus $R_{\mathrm{b}}$ decreases with the increase in concentration, recording $2.5 \Omega$ at the highest composition of 70 wt. \%. The XRD analysis reveals the semi-crystalline peak of the PVA at $\theta=20^{\circ}$ border humps of the left indicating the inclusion of the acid and the crystallinity decreases as the acid concentration increases. This result was confirmed by the DSC analysis.

\section{Acknowledgements}

The corresponding author wishes to acknowledge the assistance and contributions of management of the Faculty of Science and Technology USIM under which ERGS grant (USIM/ERGS-FST-52-50111) has been provided for the purpose of this research. 


\section{Reference}

Agrawal, S. L., \& Awadhia, A. (2004). DSC and conductivity studies on PVA based proton conducting gel electrolytes. Bulletin of Materials Science, 27(6), 523-527. http://dx.doi.org/ 10.1007/BF02707280

Ahmad Khiar, A. S., \& Arof, A. K. (2010). Conductivity Studies of Starched-based polymer electrolytes. Ionics, 16, 123-129. http://dx.doi.org/ 10.1007/s11581-009-0356-y

Gu, H.-B., Kim, J.-U., Song, H.-W., Park, G.-C. \& Park, B.-K. (2000). Electrochemical Properties of Carbon Composite Electrode with Polymer Electrolyte for Electric Double-Layer Capacitor. Electrochimica Acta, 45, 1533-1536. http://dx.doi.org/ 10.1016/S0013-4686(99)00370-9

Guirguis, O. W., \& Moselhey, M. T. H. (2012). Thermal and structural studies of poly(vinyl alcohol) and hydroxypropyl cellulose blends. Natural Science, 4, 57-67. http://dx.doi.org/ 10.4236/ns.2012.41009

Hashim, M. A, Sa'adu, L., \& A. K. Dasuki. (2012). Supercapacitor Based On Activated Carbon And Polymer Electrolyte. International Journal Of Sustainable Energy And Environmental Research, 1, 1-6.

Hashim, M. A, Sa'adu, L., Baharuddin, M., \& Dasuki, A. K. (2014). Using PVA, Methacrylate and Lauroyl Chitosan as Separator in Supercapacitors. Journal of Materials Science Research, 3(1). http://dx.doi.org/ 10.5539/jmsr.v3n1p25

Hashmi, S. A. (2013). Characteristics of Conducting Polymers for their Supercapacitive Performance. Paper presented at the Workshop on Advanced Energy Storage Materials \& Devices (WAESD). Universiti Pertahanan Nasional Malaysia (National Defense University Malaysia).

Hashmi, S. A. (2013). Electrical Double Layer Capacitor: Recent Development. Paper presented at the Workshop on Advanced Energy Storage Materials \& Devices (WAESD). Universiti Pertahanan Nasional Malaysia (National Defense University Malaysia).

Hashmi, S. A. (2013). Polymer-Based Gel electrolytes for New Generation Supercapacitors. Paper presented at the Workshop on Advanced Energy Storage Materials \& Devices (WAESD). Universiti Pertahanan Nasional Malaysia (National Defense University Malaysia).

Jelinska, N., Kalnins, M., Tupureina, V. \& Dzene, A. (2010). Poly (Vinyl Alcohol)/Poly (Vinyl Acetate) Blend Films. Scientific Journal of Riga Technical University, 21, 55-61.

Jiang, L., Vangari, M., Pryor, T., Xiao, Z. \& Korivi, N. S. (2013). Miniature Supercapacitors Based on $\begin{array}{lllll}\text { Nanocomposite Thin Films. } & \text { Microelectronic } & \text { Engineering, } & \text { 111, }\end{array}$ http://dx.doi.org/10.1016/j.mee.2013.01.030

Kumar, K. V., \& Suneeta Sundar, G. (2010). Conductivity Studies Of (PEO +KHCO3) Solid Electrolyte System and its Application as an Electrochemical Cell. Journal of Engineering Science and Technology, 5, 130-139.

Kuo, C.-W., Huang, C.-W., Chen, B.-K., Li, W.-B., Chen, P.-R., Ho, T.-H., Tseng C.-G. \& Tzi-Yi, W. (2013). Enhanced Ionic Conductivity in PAN-PEGME-LiClO4-PC Composite Polymer Electrolytes. Int. J. Electrochem. Sci., 8, 3834-3850.

Lim, D.-H., Manuel, J., Ahn, J.-H.,. Kim, J.-K., Jacobsson, P., Matic, A., Ha, J.K., Cho, K.K. \& Kim, K. W. (2012). Polymer Electrolytes Based on Poly(Vinylidene Fluoride-Co-Hexafluoropropylene) Nanofibrous Membranes Containing Polymer Plasticizers for Lithium Batteries. Solid State Ionics, 225, 631-635. http://dx.doi.org/10.1016/j.ssi.2012.03.028

Mudigoudra, B. S., Masti, S. P., \& Chougale, R. B. (2012). Thermal Behavior Of Poly (Vinyl Alcohol)/ Poly (Vinyl Pyrrolidone)/Chitosan Ternary Polymer Blend Films. Research Journal Of Recent Sciences, 1, 83-86.

Ahmad, A., Rahman, M. Y. B. A., \& Talib, I. A. (2010). Solid polymeric electrolyte of poly (ethylene) oxide- $50 \%$ epoxidized natural rubber-lithium triflate (PEO-ENR50-LiCF3SO3). Natural Science, 2(03), 190-196. http://dx.doi.org/10.4236/ns.2010.23029

Othman, N., Azahari, N. A. \& Ismail, H. (2011). Thermal Properties Of Polyvinyl Alcohol (PVOH)/Corn Starch Blend Film. Malaysian Polymer Journal, 6(6), 147-154.

Prajapati, G. K., Roshan, R., \& Gupta, P. N. (2010). Effect of plasticizer on ionic transport and dielectric properties of PVA-H3PO4 proton conducting polymeric electrolytes. Journal of Physics and Chemistry of Solids, 71, 1717-1723. http://dx.doi.org/10.1016/j.jpcs.2010.08.023 
Qiu, W.-L., Ma, X.-H., Yang, Q.-H., Fu, Y.-B \& Zong, X.-F (2004). "Novel Preparation of Nanocomposite Polymer Electrolyte and its Application to Lithium Polymer Batteries". Journal of Power Sources, 138, 245-252. http://dx.doi.org/10.1016/j.jpowsour.2004.06.061

Ragavendran, K., Kalyani, P., Veluchamy, A., Banumathi, S., Thirunakaran, R., \& Benedict, T. J. (2004). Characterization of Plasticized PEO Based Solid Polymer Electrolyte by XRD and AC Impedance Methods. Portugaliae Electrochimica Acta, 22, 149-159.

Sawada, H., Ariyoshi, Y., Lee, K., Kyokane, J., \& Kawase, T. (2000). New Approach To Highly Conductive Polymer Electrolytes: Synthesis of Gelling Fluoroalkylated End-Capped 2-Acrylamido-2-Methylpropanesulfonic Acid Copolymers Containing Poly (Oxyethylene) Units. European Polymer Journal, 36, 2523-2526. http://dx.doi.org/10.1016/S0014-3057(00)00024-0

Sotta, D., Bernard, J. \& V.-S. Moynot. (2010). Application of Electrochemical Impedance Spectroscopy to The Study of Ionic Transport in Polymer-Based Electrolytes. Progress in Organic Coatings, 69, $207-214$. http://dx.doi.org/10.1016/j.porgcoat.2010.04.011

Toney, M. F. (1992). X-Ray diffraction. In L. E. Fitzpatrick, C. R. Brundle, C. A. Evans Jr, \& S. Wilson (Comp. \& Ed.), Encyclopedia of Material characterization (pp. 198-213).

Tripathi, S. K., Gupta, A., \& Manju, K. (2012). Studies on Electrical Conductivity and Dielectric Behaviour of PVdF-HFP-PMMA-NaI Polymer Blend Electrolyte. Bull. Mater. Sci., 35, 969-975. http://dx.doi.org/10.1007/s12034-012-0387-2

Ulaganathan, M., Nithya, R., \& Rajendran, S. (2012). Surface Analysis Studies on Polymer Electrolyte Membranes Using Scanning Electron Microscope and Atomic Force Microscope. Intech, 33, 671-694.

Yang, C. C. (2004). Chemical Composition and XRD Analyses for Alkaline Composite PVA Polymer Electrolyte. Materials Letters, 58, 33-38. http://dx.doi.org/10.1016/S0167-577X(03)00409-9

Yang, R., Zhang, S., Zhang, L., \& Wenbo, L. (2013). Electrical Properties of Composite Polymer Electrolytes Based on PEO-SN-LiCF $\mathrm{SO}_{3}$. Int. J. Electrochem. Sci., 8, 10163-10169.

Zhang, Y.-J., Huang, Y.-D. \& Lei, W. (2006). Study of EVOH Based Single Ion Polymer Electrolyte: Composition and Microstructure Effects on the Proton Conductivity. Solid State Ionics, 177, 65-71. http://dx.doi.org/ 10.1016/j.ssi.2005.10.008

\section{Copyrights}

Copyright for this article is retained by the author(s), with first publication rights granted to the journal.

This is an open-access article distributed under the terms and conditions of the Creative Commons Attribution license (http://creativecommons.org/licenses/by/3.0/). 